\title{
Efficacy of Percutaneous Electrical Nerve Stimulation and Therapeutic Exercise for Older Adults with Chronic Low Back Pain: A Randomized Controlled Trial
}

\author{
Debra K. Weiner, M.D. a,b,c,g, ${ }^{*}$, Subashan Perera, Ph.D. a,d, Thomas E. Rudy, Ph.D. ${ }^{b, c, d}$, \\ Ronald M. Glick, M.D. ${ }^{c, e}$, Sonali Shenoy, P.T. ${ }^{f}$, and Anthony Delitto, Ph.D. \\ aDepartment of Medicine, University of Pittsburgh, PA, USA \\ ${ }^{b}$ Department of Anesthesiology, University of Pittsburgh, PA, USA \\ 'Department of Psychiatry, University of Pittsburgh, PA, USA \\ dDepartment of Biostatistics, University of Pittsburgh, PA, USA \\ eCenter for Integrative Medicine, University of Pittsburgh, PA, USA \\ fDepartment of Physical Therapy, University of Pittsburgh, PA, USA \\ 9Geriatric Research Education and Clinical Center, VA Pittsburgh Healthcare System, Pittsburgh, \\ PA, USA
}

\section{Abstract}

Chronic low back pain (CLBP) in older adults may be disabling and therapeutically challenging, largely because of the inefficacy and/or morbidity associated with traditional pain treatment. We conducted a randomized controlled trial in 200 men and women $\geq$ age 65 with CLBP to evaluate the efficacy of percutaneous electrical nerve stimulation (PENS) with and without general conditioning and aerobic exercise (GCAE), for reducing pain and improving physical function. Participants were randomized to receive 1) PENS, 2) control-PENS (brief electrical stimulation to control for treatment expectancy), 3) PENS + GCAE, or 4) control-PENS + GCAE, twice a week for 6 weeks. All four groups experienced significantly reduced pain (range -2.3 to -4.1 on the McGill Pain Questionnaire short form), improved self-reported disability (range -2.1 to -3.0 on Roland scale) and improved gait velocity $(0.04-0.07 \mathrm{~m} / \mathrm{sec})$, sustained at 6 months. The GCAE groups experienced significantly fewer fear avoidance beliefs immediately post-intervention and at 6 months than non-GCAE groups. There were no significant side effects. Since brief electrical stimulation (i.e., control-PENS) facilitated comparably reduced pain and improved function at 6 months as compared with PENS, the exact dose of electrical stimulation required for analgesia cannot be determined. GCAE was more effective than PENS alone in reducing fear avoidance beliefs, but not in reducing pain or improving physical function.

*Corresponding author Address: Geriatric Research Education and Clinical Center, VA Pittsburgh Healthcare System, 3471 Fifth Avenue, Suite 500, Pittsburgh, PA 15213, USA. Tel.: +1 412692 2360; fax: +1 4126922370.

Publisher's Disclaimer: This is a PDF file of an unedited manuscript that has been accepted for publication. As a service to our customers we are providing this early version of the manuscript. The manuscript will undergo copyediting, typesetting, and review of the resulting proof before it is published in its final citable form. Please note that during the production process errors may be discovered which could affect the content, and all legal disclaimers that apply to the journal pertain. 


\section{INTRODUCTION}

Chronic low back pain (CLBP) is one of the most common, disabling, diagnostically complex, and therapeutically challenging of all chronic pain disorders in older adults. Approximately $42 \%$ of older adults report having had an episode of low back pain during the past year, and an estimated 20\% of these individuals have CLBP(65). Those who develop chronic pain incur the greatest suffering and expenditure of health care resources $(11,66)$. Costs and morbidity are compounded by currently accepted, although often misleading diagnostic strategies and ineffective treatment.

The standard of care for the majority of older adults with CLBP begins with oral analgesics and exercise. Patients who do not respond or experience limiting morbidity may have few safe therapeutic alternatives. Because of this dilemma, complementary and alternative modalities (CAM) have been increasingly sought by chronic pain sufferers with greater than 15 million Americans having tried acupuncture (4). Because of the relative paucity of high quality clinical trials of acupuncture and related modalities, these forms of CAM remain outside of mainstream medical practice. Controlled clinical trials of traditional Chinese acupuncture for the treatment of CLBP have met with conflicting results $(9,12)$. These studies have had a number of methodological constraints such as not excluding participants experiencing an acute flare of pain or those who have previously received acupuncture, and not tracking treatments sought during the follow-up period. Because of these constraints, the degree to which their findings can be generalized to clinical practice is unknown. Clinical practice guidelines recently published by the American Pain Society and American College of Physicians indicate fair evidence in support of recommending acupuncture for the treatment of CLBP (13).

Patients with CLBP become deconditioned because of chronic pain-associated inactivity (16, 36-38), thus analgesia is typically combined with reconditioning when rehabilitating patients with chronic pain (27). The therapeutic benefits of exercise for older adults with CLBP have not been examined in the context of a randomized controlled clinical trial. Studies performed in younger individuals with CLBP indicate that exercise is moderately effective for reducing pain and for improving function $(13,25)$.

Percutaneous electrical nerve stimulation (PENS) is a contemporary form of electroacupuncture guided by principles of neuroanatomy and neurophysiology that has been shown to have immediate efficacy for reducing pain younger patients with low back pain (30). We have published a preliminary trial demonstrating the short term efficacy (3 months) of PENS for reducing pain and improving self-reported disability in community dwelling older adults with CLBP (67). Therapeutic exercise had no additional benefit for reducing pain or improving function in this initial study. The results presented below serve to extend these findings. Specifically, the objective of this study was to examine the impact of PENS with and without general conditioning and aerobic exercise for reducing pain and improving function in older adults with CLBP.

\section{METHODS}

\section{Design Overview}

The study was approved by the University of Pittsburgh's Institutional Review Board. Participant flow is shown in Figure 1. Participants were first telephone-screened using a structured questionnaire $(n=635)$. Those who met the inclusion and exclusion criteria in Table $1(n=288)$ were invited for an on-site history, physical examination and EKG performed by one of the investigators (DW). 


\section{Setting and Participants}

All evaluations and interventions were performed in an outpatient research facility attached to the Older Adult Pain Management Program at the University of Pittsburgh. Participants were community dwelling older adults with CLBP. All participants signed informed consent prior to participating in any of the on site procedures.

\section{Sample Size Justification}

We based our planned sample size on information from prior studies $(28-30,47,67)$, and having adequate statistical power for testing the hypotheses of interest with the main outcomes pain intensity (McGill Pain Questionnaire) and pain-related disability (Roland disability) scale. Fifty randomized participants per treatment group were estimated to provide statistical power in the range of: $82-99 \%$ for detecting statistical significance of an effect size in the $0.46-0.82$ range corresponding to a reduction in pain intensity due to PENS and/or GCAE immediately after intervention; and $82-94 \%$ for detecting statistical significance of an effect size in the $0.37-0.45$ range corresponding to a reduction in pain-related disability due to PENS and/or GCAE immediately after intervention.

\section{Randomization and Interventions}

Participants were randomized to one of four groups using a stratified blocked randomization scheme and statistical software for random deviate generation. The randomization groups were: 1) PENS, 2) control-PENS, 3) PENS + general conditioning and aerobic exercise (GCAE), and 4) control-PENS + GCAE. Randomization strata were based on age group (65-74 and 75 + ) and gender $(7,8,49)$. A fixed block size of 20 was used to ensure equal numbers of participants were randomized to the four treatment groups. One of the study investigators (TER) created and monitored the implementation of the randomization scheme. He communicated the randomization assignments only to the treating clinicians (i.e., acupuncturist and physical therapist). The research associate who collected the outcomes data was masked to group assignment. All interventions were administered twice a week for six weeks.

PENS Procedure-All PENS and control-PENS was administered by an acupuncturist (RMG) masked to whether participants were randomized to receive GCAE. All participants were instructed not to discuss their group assignment with the acupuncturist during PENS/ control-PENS sessions or with project staff collecting outcomes data who were also masked to group assignment. Both PENS and control-PENS was administered according to the technique of Craig and colleagues (30), using 32 gauge $40 \mathrm{~mm}$ needles placed just below the skin into subcutaneous fascia, approximately $15 \mathrm{~mm}$ in depth (i.e., a depth adequate to attain needle stability). Ten needles were used for each session, placed bilaterally at dermatomal, myotomal, scleratomal, and sympathetic levels corresponding to T12, L3, L5, and S2, and the motor point for the piriformis muscle. A crossed in and out montage was used in the event that participants' pain was unilateral.

Electrical stimulation was applied for 30 minutes, using a specific pattern (alternating positive and negative leads) using the Pantheon Research PENS electrostimulator. The frequency used was determined by response to the previous treatment session, as outlined in the algorithm depicted in Figure A (see PAIN on line) (31). The amplitude was set in order to create a perceived stimulus of moderate intensity and was adjusted by the acupuncturist throughout the session to maintain constant stimulus perceptibility. Participants also had two needles placed at the T-12 level and transient high frequency electrical stimulation provided as per the controlPENS procedure, described below.

Control-PENS Procedure-Ten 32-gauge $40 \mathrm{~mm}$ acupuncture needles were applied in identical locations and depth as in the PENS condition to maximize credibility. In addition, 
two needles were placed bilaterally at the T-12 dermatome. As with PENS, all sessions lasted 30 minutes. The acupuncturist delivered electrical stimulation only at the T-12 dermatome using the same Pantheon Research PENS electrostimulator unit used for PENS. A frequency of $100 \mathrm{~Hz}$ was used for all 12 treatment sessions, as it has been demonstrated that individuals quickly accommodate to higher frequencies (35). Five minutes following the initiation of electrical stimulation, the electrostimulator unit was turned off to avoid the delivery of potentially therapeutic microcurrent.

GCAE Procedures-The GCAE program was enacted on site, under the supervision of a physical therapist (SS) and at home. Exercises included both general conditioning (strength and flexibility) and aerobic components and was modeled after a fitness program developed for the treatment of younger individuals with CLBP $(28,29)$. All on site sessions lasted 60 minutes. Prior to initiating the GCAE program, the physical therapist conducted a baseline evaluation to confirm participant safety and to determine the appropriate starting intensity and volume for the general conditioning and aerobic portions of the program.

The on site aerobic exercises were performed on a treadmill or stationary bicycle, depending on the participants' preference, with duration modified by participant tolerance (maximum 30 minutes). The general conditioning regimen and criteria for progression are summarized in Table A (presented as supplementary data in PAIN on line). Participants were instructed to perform each exercise for 2 minutes followed by a 1 minute rest period.

The home exercise program (HEP) consisted of flexibility exercises and a graded walking program performed three times a week for six weeks. The flexibility exercises included 12 muscle stretches targeting lower extremity and low back musculature. Each exercise was performed for 3 repetitions, 3 times a day; in the morning, afternoon, and evening. Participants were also instructed to walk for 30 minutes a day (beyond the amount of walking performed in the context of routine daily activities) or to tolerance. Participants recorded exercises performed in a diary that included frequency, duration and perceived difficulty, which the treating physical therapist used to recommend exercise progression.

\section{Outcomes and Follow-up}

All primary and secondary outcome measures were collected at baseline, within one week of completing the 6 week intervention, and 6 months later.

Primary Outcome Measures-were pain intensity measured with the short form of the McGill Pain Questionnaire (50) and pain thermometer (53), and self-reported disability with the Roland and Morris questionnaire (53), instruments that have been validated in community dwelling older adults with CLBP $(64,67)$.

Secondary Outcome Measures-were chosen to capture the multidimensional experience of chronic pain and included:

1. Self-reported physical function measured with the pain subscale of the Functional Status Index (43) and the Physical Activity Scale for the Elderly (63).

2. Performance-based physical function measured with gait speed over 25 feet $(5,32$, $34,44)$; timed repetitive chair rise (i.e., 5 consecutive times) (59); and timed stair climbing $(18,26)$.

3. Psychosocial function was measured with the Geriatric Depression Scale (30 item (70)); the Chronic Pain Self-Efficacy Scale (1); the Catastrophizing Scale of the Cognitive Strategies Questionnaire (54); and the Fear-Avoidance Beliefs Questionnaire (FABQ-scale 2) (60). 
4. Self-rated health was measured using standard methodology $(3,39,40,51,56)(52)$.

5. Sleep was assessed using the Pittsburgh Sleep Quality Index (10).

6. Health-Related Quality of Life, assessed at baseline and 6-months follow-up, was measured with the Medical Outcomes Study 36 Item Short Form Health Survey (SF 36) (62).

Demographic factors (age, gender, ethnicity, marital and educational status), medication dose and frequency, medical comorbidity measured with the cumulative illness rating scale (48) and body mass index were also assessed at baseline.

Treatment credibility was evaluated at sessions 2 and $8(6,45)$. Independent global rating of improvement on a 5-point scale also was made by each of the treating clinicians, and the participant's own rating of his or her improvement (55).

\section{Statistical Analysis}

SAS ${ }^{\circledR}$ version 9 (SAS Institute, Inc., Cary, North Carolina) was used for all statistical analysis. Participant characteristics and baseline measurements of all outcomes were compared across the four treatment groups using one-way analysis of variance, Kruskal-Wallis, chi-square and Fisher's exact tests, as appropriate, depending on the nature and distribution of the variable. Participant characteristics and baseline measurements of all outcomes were also compared between those who stayed in study and those who discontinued using independent samples $t$-, Wilcoxon rank sum, chi-square and Fisher's exact tests, as appropriate, to determine whether dropouts were systematically different from those with complete data. To characterize withingroup change over time, we summarized baseline to post-intervention and 6-month change with descriptive statistics and paired-sample $t$-tests. For the main analysis comparing treatment arms, a mixed linear model was fit using the SAS ${ }^{\circ}$ MIXED procedure with change from baseline of each outcome as the response variable; randomized treatment group (PENS/Sham/ $\mathrm{PENS}+\mathrm{PT} / \mathrm{Sham}+\mathrm{PT}$ ), time (post-intervention/6-month follow-up) and their interaction as main fixed effects of interest; baseline value of the outcome as a fixed-effect covariate; and a participant random effect to account for multiple measurements over time from the same participants. Appropriate post hoc means contrasts were made for pairwise comparisons between various treatment groups of interest, both immediately after intervention and after 6 months. Within-group effect sizes were computed as the ratio between mean change and baseline standard deviation, and between-group effect sizes as that between adjusted betweengroup difference and baseline standard deviation (46). Effect sizes were interpreted as 0.20 for small, $0.50-0.60$ for moderate, and 0.80 for large $(14,15)$. Kruskal-Wallis and Wilcoxon rank sum tests were used to make between-group comparisons in ordinal global rating of change. The analysis was repeated with last-value-carried-forward and multiple imputation approaches to assess sensitivity of the results to the mechanism that generated missing data. Treatment credibility ratings were compared between groups using Kruskal-Wallis tests, and associations between treatment credibility ratings and changes in primary outcomes were explored using Spearman rank correlation coefficients.

\section{RESULTS}

Participant characteristics are shown in Table 2. There were no significant differences between groups. The overall dropout rate was $8 \%$ (Figure 1). Baseline participant characteristics were similar between dropouts and study completers except for greater prevalence of opioid use among dropouts. Results did not meaningfully change when missing data was accounted for using last-value-carried-forward or multiple imputation approaches (data not shown [dns]). 
Treatment group $\times$ time interaction was not statistically significant for all outcomes except chair rise time $(p=0.0330)$. Tables $3 \mathrm{~A}$ and $3 \mathrm{~B}$ summarize the post-intervention and 6 months between group comparisons. At post-intervention, significant differences were only seen between the PENS+GCAE group and the PENS group, and between the control PENS+GCAE group and the control PENS groups. CGAE improved fear avoidance beliefs with or without PENS at post-intervention, with persistence of this difference observed at 6 months for the PENS+GCAE versus PENS comparison only.

Baseline to post-intervention (after 6 weeks) and 6-month follow-up changes in the primary and secondary outcomes are summarized in Table 4. Changes in the primary outcome measures are shown in Figure 2. At post-intervention, all four groups experienced significant reduction in present pain intensity (short form McGill Pain Questionnaire), average and strongest pain during the prior week measured with the pain thermometer, self-reported disability on the Roland scale, and significant improvement in physical performance measured with gait velocity. Chair rise time decreased significantly in all but the control PENS group. Chronic pain self-efficacy improved in all except the PENS only group. Fear avoidance beliefs decreased most significantly in the participants who received GCAE (i.e., the PENS + GCAE and the control PENS + GCAE groups). There was no significant change in sleep quality, depressive symptoms, catastrophizing (except in the PENS only group), SF-36 composite mental and physical (except Control PENS+CGAE group) scores, or stair climb time (except Control PENS+CGAE group). At 6 months, reduction in pain intensity and self-reported disability persisted in all groups. Improved gait speed and chair rise time persisted in all but the PENS only group where the improvement was still marginally significant. Improved selfefficacy was still significant in the PENS + GCAE group and decreased fear avoidance beliefs remained significant in the PENS + GCAE and the control PENS + GCAE groups.

There were no significant between-group differences in perceived treatment credibility at Session 2 and at Session 8. There were (marginally) significant correlations ( $r$ ) between some treatment credibility ratings at Session 2 and improvements in primary outcomes only in the PENS group $(r=0.25-0.45 ; p<0.09)$. At Session 8 , these associations were stronger and present in all four groups (PENS $r=0.27-0.53, p<0.08$; PENS+GCAE $r=0.29-0.39, p<0.07$; control PENS r=0.27-0.44, $p<0.08$; control PENS+GCAE $r=0.27-0.48, p<0.09$ ). There were no differences in self-rated global improvement, or health care utilization during the follow-up period between the four participant groups (dns). Adherence with GCAE was also comparable groups (dns). There were no significant intervention-associated adverse effects. One participant dropped out because of increased back pain.

\section{DISCUSSION}

This is the first randomized controlled clinical trial to examine the sustained efficacy of PENS and/or therapeutic exercise for reducing pain and improving function in older adults with CLBP. Results indicate six weeks of twice weekly PENS, whether delivered using electrical stimulation for 30 minutes or 5 minutes, affords sustained pain reduction for 6 months and is associated with no significant side effects. General conditioning and aerobic exercise (GCAE) did not significantly enhance pain reduction or functional improvement above and beyond that associated with PENS or the control-PENS procedure, but GCAE did afford significantly greater reduction in fear avoidance beliefs that was sustained at 6 months.

The magnitude of pain reduction and functional improvement observed is comparable to that of other multidisciplinary treatment trials for CLBP in patients of heterogeneous ages (27). The clear advantage of PENS is the lack of significant side effects. Traditional oral analgesics (e.g., non-steroidal anti-inflammatory drugs [NSAIDs], opioids) are often associated with serious side effects including renal impairment, cerebrovascular accidents, heart failure and 
gastrointestinal bleeding with NSAIDS (71) and delirium, falls and hip fractures with opioids $(23,24,57)$. None of these are associated with PENS. In our experience, minor bruising and pain flares occur in less than $5 \%$ of patients and significant side effects are absent.

The comparable reduction in pain in participants who received PENS as well as those who received the control-PENS procedure should be highlighted. These findings are in distinct contrast to our previously published study in which the control-PENS condition employed placement of acupuncture needles without any electrical stimulation (67). In this previous trial, control-PENS participants (who also received a flexibility and physical reconditioning exercise program combined with education) experienced no improvement in pain or physical function, either immediately following completion of the intervention, or 3 months later and, as with the current study, participants who received PENS experienced significant improvement that was sustained at 3 months. The reason for these differences can only be speculated upon. It has recently been demonstrated that pain processing within the brain is at least in part modulated by expectancy (i.e., placebo disguised as viable pain treatment $(19,61)$ and that many of the brain areas that are activated by placebo analgesia overlap with those involved in acupuncture analgesia (19). Because treatment expectancy was comparable among the four randomized groups, one cannot exclude the possibility that treatment expectancy accounted for the change in outcomes observed. The modest association between treatment credibility and pain reduction within groups supports this possibility. Additionally, the brief electrical stimulation delivered as part of the control-PENS procedure in the current but not the previous study, may have had analgesic effects. The fact that pain reduction and improved function were sustained for months makes it unlikely that the placebo response alone was responsible for the changes observed, but additional studies are warranted.

It is noteworthy that there was no significant difference in the primary outcomes (i.e., pain, function) in participants who received GCAE as compared with those who did not. Our previous trial also demonstrated that an intervention that was less vigorous with regard to exercise intensity and not progressed in a systematic fashion was associated with no measurable benefits (67). It may be useful to consider these findings in the context of recently published data suggesting that neuropsychological performance (NP) is impaired in older adults with CLBP and that NP may mediate the relationship between pain and physical function (68). Perhaps CLBP rehabilitation programs should include interventions that focus on the neuropsychological effects of chronic pain $(2,20-22,41,58)$ and the impact of such interventions on physical function tested.

Differences between our study and randomized controlled trials of traditional Chinese acupuncture (TCA) for the treatment of CLBP should be highlighted. Two large trials of TCA have had conflicting results $(9,12)$. A recently published randomized controlled trial in participants of mean age 59 and mean pain duration 15 years demonstrated no significant difference between acupuncture and sham acupuncture for reducing pain or improving function (9). Improvement in both groups was sustained at 52 weeks, but as compared with our study, no information was provided about treatments sought during the follow-up period (e.g., ongoing acupuncture). In addition, approximately one-third of participants at baseline had prior exposure to acupuncture which was presumably positive, making it difficult to determine the influence of treatment expectations on outcomes. Finally, whether participants experiencing an acute flare of pain were excluded (i.e., those in whom pain would be expected to resolve spontaneously) is unknown. The other trial randomized participants to receive TCA, therapeutic massage, or self-care education and found no benefits of TCA (12).

It should be noted that the participants in our study were independent, but relatively frail as evidenced by their baseline gait speed that was near the lowest quartile reported for community dwelling older adults (33). The lack of improvement in response to GCAE, therefore, may have 
been related to inadequate intensity of the intervention. While GCAE did not significantly improve pain or function, it did reduce fear avoidance beliefs immediately following the intervention period and at 6 months. In younger patients with chronic pain, fear avoidance beliefs have been found to significantly impact function (17). The reduction in fear avoidance beliefs in our participants was not, however, associated with improved function. Whether this finding is related to the neuropsychological factors noted above, inadequate intensity of the GCAE intervention, or other unidentified factors cannot be determined from our data. Future studies should explore interventions that are consistent with the GCAE principles (e.g., graded program, criteria for progression, etc.) but include activities that are more specific to everyday functional activities in order to better link reduction in fear avoidance to physical function.

Another study limitation is that participants were relatively frail, thus the ability of our results to be generalized to more robust older adults cannot be determined. We also cannot determine the extent to which our study findings can be applied to older adults with lumbar spinal stenosis (LSS), a condition that occurs commonly in older adults, but is challenging to diagnose accurately. Imaging evidence of moderate to severe central canal stenosis is common in older adults and has no predictive validity for the presence of pain (42). Preliminary evidence also suggests that $50 \%$ of older adults with CLBP and neurogenic claudication have other pain comorbidities that could explain their pain [e.g., hip arthritis, myofascial dysfunction, fibromyalgia] (69). Leg pain was our only proxy measure of LSS, and it was not significantly different across the four treatment groups at baseline. A final limitation of our study is that we have considered a large number of secondary outcomes in addition to the preplanned main outcomes. Significant differences in secondary outcomes should be interpreted with the understanding that results may be somewhat liberal.

In conclusion, lumbar PENS administered twice a week for 6 weeks to community dwelling older adults with CLBP is safe and well-tolerated. It reduces pain and improves self-reported pain-associated disability, and these benefits are sustained after 6 months. Minimal electrical stimulation (i.e., 5 minutes as compared with 30 minutes) has similar benefits. General conditioning and aerobic exercise does not further reduce pain or improve function. Given its safety and efficacy, costs associated with lumbar PENS should be reimbursed by third party payers. The efficacy of particular therapeutic exercise protocols should be demonstrated in older adults with CLBP before they are prescribed routinely.

\section{Supplementary Material}

Refer to Web version on PubMed Central for supplementary material.

\section{Acknowledgments}

Financial Disclosures: Weiner - none; Perera - Dr. Perera received funding from Eli Lily \& Co. to do observational research; Rudy - none; Glick - none; Shenoy - none; Delitto - none.

Funding/Support: This work was supported in by Grant R01 AT000985 from the National Center for Complementary and Alternative Medicine and the National Institute on Aging, National Institutes of Health. Dr. Perera was also supported by the Pittsburgh Claude D. Pepper Older Americans Independence Center (NIA P30 AG-024827).

Role of the Sponsor: Neither the National Institute on Aging nor the National Center for Complementary and Alternative Medicine participated in the design or conduct of the study, in the collection, analysis, or interpretation of the data, or in the preparation, review, or approval of the manuscript. 


\section{REFERENCES}

1. Anderson KO, Noel Dowds B, Pelletz RE, Edwards WT, Peeters-Asdourian C. Development and initial validation of a scale to measure self-efficacy beliefs in patients with chronic pain. Pain 1995;63:7784. [PubMed: 8577493]

2. Apkarian AV, Sosa Y, Krauss BR, Thomas PS, Fredrickson BE, Levy RE, Harden RN, Chialvo DR. Chronic pain patients are impaired on an emotional decision-making task. Pain 2004;108:129-136. [PubMed: 15109516]

3. Bath PA. Self-rated health as a risk factor for prescribed drug use and future health and social service use in older people. Journals of Gerontology; Series A, Biological Sciences \& Medical Sciences 1999;54(11):M565-M570.

4. Berman BM, Bausell RB. The use of non-pharmacological therapies by pain specialists. Pain 2000;85:313-315. [PubMed: 10781905]

5. Bohannon RW. Comfortable and maximum walking speed of adults aged 20-79 years: Reference values as determinants. Age and Aging 1997;26:15-19.

6. Borkovec TD, Nau SD. Credibility of analogue therapy rationales. J Behav Ther Exp Psychiat 1972;3:257-260.

7. Boston JR, Rudy TE, Lieber SJ, Stacy BR. Measuring treatment effects on repetitive lifting for patients with chronic low back pain: Speed, style, and coordination. Journal of Spinal Disorders 1995;8:342351. [PubMed: 8563153]

8. Boston JR, Rudy TE, Mercer SR, Kubinski JA. A measure of body movement coordination during repetitive dynamic lifting. IEEE Transactions on Rehabilitation Engineering 1993;1:137-144.

9. Brinkhaus B, Witt CM, Jena S, Linde K, Streng A, Wagenpfeil S, Irnich D, Walther H-U, Melchart D, Willich SN. Acupuncture in pateints with chronic low back pain: a randomized controlled trial. Archives of Internal Medicine 2006;166:450-457. [PubMed: 16505266]

10. Buysse DJ, Reynolds CF, Monk TH, Berman SR, Kupfer DJ. The Pittsburgh Sleep Quality Index: a new instrument for psychiatric practice and research. Psychiatry Research 1989;28:193-213. [PubMed: 2748771]

11. Carey TS, Evans A, Hadler N, Kalsbeek W, McLaughlin C, Fryer J. Care-seeking among individuals with chronic low back pain. Spine 1995;20(3):312-317. [PubMed: 7732467]

12. Cherkin DC, Eisenberg D, Sherman KJ, Barlow W, Kaptchuk TJ, Street J, Deyo R. Randomized trial comparing traditional chinese medical acupuncture, therapeutic massage, and self-care education for chronic low back pain. Archives of Internal Medicine 2001;161(8):1081-1088. [PubMed: 11322842]

13. Chou R, Huffman LH. Nonpharmacologic therapies for acute and chronic low back pain: a review of the evidence for an American Pain Society/American College of Physicians clinical practice guideline. Annals of Internal Medicine 2007;147:492-504. [PubMed: 17909210]

14. Cohen FA. Postsurgical pain relief: Patients' status and nurses' medication choices. Pain 1980;9:265274. [PubMed: 7454388]

15. Cohen, J., editor. Statistical Power Analysis for the Behavioral Sciences. Hillsdale, NJ: Lawrence Erlbaum Associates; 1987.

16. Crombez G, Vervaet L, Lysens R, Baeyens F, Eelen P. Avoidance and confrontation of painful, backstraining movements in chronic back pain patients. Behavior Modification 1998;22(1):62-77. [PubMed: 9567737]

17. Crombez G, Vlaeyen JW, Heuts PH, Lysens R. Pain-related fear is more disabling than pain itself: evidence on the role of pain-related fear in chronic back pain disability. Pain 1999;80(1-2):329-339. [PubMed: 10204746]

18. Cutler RB, Fishbain DA, Steele Rosomoff R, Rosomoff HL. Outcomes in treatment of pain in geriatric and younger age groups. Archives of Physical Medicine and Rehabilitation 1994;75:457-464. [PubMed: 8172508]

19. Dhond RP, Kettner N, Napadow V. Do the neural correlates of acupuncture and placebo effects differ? Pain 2007;128:8-12. [PubMed: 17267130]

20. Eccleston C. Chronic pain and attention: a cognitive approach. British Journal of Clinical Psychology 1994;33:535-547. [PubMed: 7874045] 
21. Eccleston C. Chronic pain and distraction: An experimental investigation into the role of sustained and shifting attention in the processing of chronic persistent pain. Behavioral Research and Therapy 1995;33(4):391-405.

22. Eccleston C, Crombez G, Aldrich S, Stannard C. Attention and somatic awareness in chronic pain. Pain 1997;72:209-215. [PubMed: 9272805]

23. Ensrud KE, Blackwell T, Mangione CM, et al. Central nervous system active medications and risk for falls in older women. Journal of the American Geriatrics Society 2002;50:1629-1637. [PubMed: 12366615]

24. Ersek M, Cherrier MM, Overman SS, Irving GA. The cognitive effects of opioids. Pain Management Nursing 2004;5(2):75-93. [PubMed: 15297954]

25. Ferreira ML, Ferreira PH, Latimer J, Herbert RD, Hodges PW, Jennings MD, Maher CG, Refshauge KM. Comparison of general exercise, motor control exercise and spinal manipulative therapy for chronic low back pain: A randomized trial. Pain 2007;131:31-37. [PubMed: 17250965]

26. Fisher NM, Gresham GE, Abrams M, Hicks J, Horrigan D, Pendergast DR. Quantitative effects of physical therapy on muscular and functional performance in subjects with osteoarthritis of the knees. Archives of Physical Medicine and Rehabilitation 1993;74:840-847. [PubMed: 8347069]

27. Flor H, Fydrich T, Turk DC. Efficacy of multidisciplinary pain treatment centers: a meta-analytic review. Pain 1992;49:221-230. [PubMed: 1535122]

28. Frost H, Klaber Moffett JA, Moser JS, Fairbank JCT. Randomised controlled trial for evaluation of fitness programme for patients with chronic low back pain. British Medical Journal 1995;310(6973): 151-154. [PubMed: 7833752]

29. Frost H, Lamb SE, Klaber Moffett JA, Fairbank JC, Moser JS. A fitness programme for patients with chronic low back pain: 2-year follow-up of a randomised controlled trial. Pain 1998;75(2-3):273279. [PubMed: 9583763]

30. Ghoname EA, Craig WF, White PF, Ahmed HE, Hamza MA, Henderson BN, Gajraj NM, Huber PJ, Gatchel RJ. Percutaneous electrical nerve stimulation for low back pain - a randomized crossover study. Journal of the American Medical Association 1999;281:818-823. [PubMed: 10071003]

31. Ghoname EA, Craig WF, White PF, et al. The effect of stimulus frequency on the analgesic response to percutaneous electrical nerve stimulation in patients with chronic low back pain. Anesthesia and Analgesia 1999;88:841-846. [PubMed: 10195535]

32. Guralnik JM, Ferrucci L, Pieper CF, Leveille SG, Markides KS, Ostir GV, Studenski S, Berkman LF, Wallace RB. Lower extremity function and subsequent disability: consistency across studies, predictive models, and value of gait speed alone compared with the short physical performance battery. Journal of Gerontology: MEDICAL SCIENCES 2000;55A(4):M221-M231.

33. Guralnik JM, Ferrucci L, Simonsick EM, Salive ME, Wallace RB. Lower-extremity function in persons over the age of 70 years as a predictor of subsequent disability. New England Journal of Medicine 1995;332:556-561. [PubMed: 7838189]

34. Guralnik JM, Simonsick EM, Ferrucci L, Glynn RJ, Berkman LF, Blazer DG, Scherr PA, Wallace RB. A short physical performance battery assessing lower extremity function: Association with selfreported disability and prediction of mortality and nursing home admission. Journal of Gerontology: Medical Sciences 1994;49(2):M85-M94.

35. Helms, JH. Acupuncture Energetics: A Clinical Approach for Physicians. Berkley, CA: Medical Acupuncture Publishers; 1995.

36. Hicks GE, Simonsick EM, Harris TB, Newman AB, Weiner DK, Nevitt MA, Tylavsky FA. Crosssectional associations between trunk muscle composition, back pain and physical function in the Helath ABC study. Journal of Gerontology: Medical Sciences 2005;60A(7):882-887.

37. Hultman G, Nordin M, Saraste H, Ohlsen H. Body composition, endurance, strength, cross-sectional area, and density of MM erector spinae in men with and without low back pain. Journal of Spinal Disorders 1993;6(2):114-123. [PubMed: 8504222]

38. Hutten MM, Hermens HJ, Ijzerman MJ, Lousberg R, Zilvld G. Distribution of psychological aspects in subgroups of chronic low back pain patients divided on the score of physical performance. International Journal of Rehabilitation Research 1999;22(4):261-268. [PubMed: 10669975]

39. Idler EL, Benyamini Y. Self-rated health and mortality: a review of twenty-seven community studies. Journal of Health \& Social Behavior 1997;38(1):21-37. [PubMed: 9097506] 
40. Idler EL, Russell LB, Davis D. Survival, functional limitations, and self-rated health in the NHANES I epidemiologic follow-up study, 1992. American Journal of Epidemiology 2000;152(9):874-883. [PubMed: 11085400]

41. Jamison RN, Schein JR, Vallow S, Ascher S, Vorsanger GJ, Katz NP. Neuropsychological effects of long-term opioid use in chronic pain patients. Journal of Pain \& Symptom Management 2003;26(4): 913-921. [PubMed: 14527760]

42. Jarvik JJ, Hollingworth W, Heagerty P, Haynor DR, Deyo RA. The longitudinal assessment of imaging and disability of the back (LAIDBack) study: baseline data. Spine 2001;26(10):1158-1166. [PubMed: 11413431]

43. Jette AM. Functional Status Index: Reliability of a chronic disease evaluation instrument. Archives of Physical Medicine and Rehabilitation 1980;61:395-401. [PubMed: 7416929]

44. Judge JO, Schechtman K, Cress E, Group F. The relationship between physical performance measures and Independence in instrumental activities of daily living. Journal of the American Geriatrics Society 1996;44:1332-1341. [PubMed: 8909349]

45. Kazdin AE. Acceptability of alternative treatments for deviant child behavior. Journal of Applied Behavior Analysis 1980;13:259-273. [PubMed: 7380752]

46. Kazis L, Anderson J, Meenan R. Effect sizes for interpreting changes in health status. Med Care 1989;27:S178-S189. [PubMed: 2646488]

47. Leibing E, Leonhardt U, Koster G, Goerlitz A, Rosenfeldt J-A, Hilgers R, Ramadori G. Acupuncture treatment of chronic low-back pain - a randomized, blinded, placebo-controlled trial with 9-month follow-up. Pain 2002;96(1-2):189-196. [PubMed: 11932074]

48. Linn BS, Linn MW, Gurel L. Cumulative Illness Rating Scale. Journal of the American Geriatrics Society 1968;16(5):622-626. [PubMed: 5646906]

49. Manton KG, Corder L, Stallard E. Chronic disability trends in elderly United States populations: 1982-1994. Proc Natl Acad Sci USA 1997;94:2593-2598. [PubMed: 9122240]

50. Melzack R. The short-form McGill pain questionnaire. Pain 1987;30:191-197. [PubMed: 3670870]

51. Mossey JM, Shapiro MA. Self-rated health: a predictor of mortality among the elderly. Am. J. Public Health 1982;72:800-808. [PubMed: 7091475]

52. Reyes-Gibby CC, Aday L, Cleeland C. Impact of pain on self-rated health in the community-dwelling older adults. PAIN 2002;95(1-2):75-82. [PubMed: 11790469]

53. Roland M, Morris R. A study of the natural history of back pain-part I: Development of a reliable and sensitive measure of disability in low-back pain. Spine 1983;8:141-144. [PubMed: 6222486]

54. Rosensteil AK, Keefe FJ. The use of coping strategies in chronic low back pain patients: relationship to patient characteristics and current adjustment. Pain 1983;17:33-44. [PubMed: 6226916]

55. Rudy TE, Turk DC, Kubinski JA, Zaki HS. Differential treatment responses of TMD patients as a function of psychological characteristics. Pain 1995;61:103-112. [PubMed: 7644232]

56. Schoenfeld DE, Malmrose LC, Blazer DG, Gold DT, Seeman TE. Self-rated health and mortality in the high-functioning elderly --a closer look at healthy individuals: MacArthur field study of successful aging. Journal of Gerontology 1994;49(3):M109-M115. [PubMed: 8169332]

57. Shorr RI, Griffin MR, Daugherty JR, Ray WA. Opioid analgesics and the risk of hip fracture in the elderly: codeine and propoxyphene. J Gerontol 1992;47:M111-M115. [PubMed: 1624693]

58. Tassain V, Attal N, Fletcher D, Brasseur L, Degieux P, Chauvin M, Bouhassira D. Long term effects of oral sustained release morphne on neuropsychological performance in patients with chronic noncancer pain. Pain 2003;104:389-400. [PubMed: 12855350]

59. Tinetti ME. Performance-oriented assessment of mobility problems in elderly patients. Journal of the American Geriatrics Society 1986;95(34):2.

60. Waddell G, Newton M, Henderson I, Somerville D, Main CJ. A fear-avoidance beliefs questionnaire (FABQ) and the role of fear-avoidance beliefs in chronic low back pain and disability. Pain 1993;52:157-168. [PubMed: 8455963]

61. Wager TD, Rilling JK, Smith EE, Sokolik A, Casey KL, Davidson RJ, et al. Placebo-induced changes in fMRI in the anticipation and experience of pain. Science 2004;303:1162-1167. [PubMed: 14976306] 
62. Ware JE, Sherbourne C. The MOS 36-item short-form survey (SF-36): I. Conceptual framework and item selection. Med Care 1992;30:473-483. [PubMed: 1593914]

63. Washburn RA, Smith KW, Jette AM, Janney CA. The Physical Activity Scale for the Elderly (PASE): development and evaluation. Journal of Clinical Epidemiology 1993;46:153-162. [PubMed: 8437031]

64. Weiner D, Pieper C, McConnell E, Martinez S, Keefe F. Pain measurement in elders with chronic low back pain: traditional and alternative approaches. Pain 1996;67:461-467. [PubMed: 8951942]

65. Weiner DK, Haggerty CL, Kritchevsky SB, Harris T, Simonsick EM, Nevitt M, Newman A. for the Health, A., and Body Composition Research Group. How does low back pain impact physical function in independent, well-functioning older adults? Evidence from the Health ABC cohort and implications for the future. Pain Medicine 2003;4(4):311-320. [PubMed: 14750907]

66. Weiner DK, Kim Y-S, Bonino P, Wang T. Low back pain in older adults: Are we utilizing health care resources wisely? Pain Medicine 2006;7(2):143-150. [PubMed: 16634727]

67. Weiner DK, Rudy TE, Glick RM, Boston JR, Lieber SJ, Morrow L, Taylor S. Efficacy of percutaneous electrical nerve stimulation (PENS) for the treatment of chronic low back pain in older adults. Journal of the American Geriatrics Society 2003;51:599-608. [PubMed: 12752833]

68. Weiner DK, Rudy TE, Morrow L, Slaboda J, Lieber SJ. The relationship between pain, neuropsychological performance, and physical function in community-dwelling older adults with chronic low back pain. Pain Medicine 2006;7(1):60-70. [PubMed: 16533199]

69. Weiner DK, Sakamoto S, Perera S, Breuer P. Chronic low back pain in older adults: prevalence, reliability, and validity of physical examination findings. Journal of the American Geriatrics Society 2006;54:11-20. [PubMed: 16420193]

70. Yesavage JA, Brink TL, Rose TL, Lum O. Development and validation of a geriatric depression screening scale: A preliminary report. Journal of Psychiatric Research 1983;17:37-49. [PubMed: 7183759]

71. Zhang W, Moskowitz RW, Nuki G, Abramson S, Altman RD, Arden N, Bierma-Zeinstra S, Brandt KD, Croft P, Doherty M, Dougados M, Hochberg M, Hunter DJ, Kowh K, Lohmander LS, Tugwell P. OARSI recommendations for the management of hip and knee osteoarthritis, Part I: Critical appraisal of existing treatment guidelines and systematic review of current research evidence. Osteoarthritis and Cartilage 2007;15:981-1000. [PubMed: 17719803] 


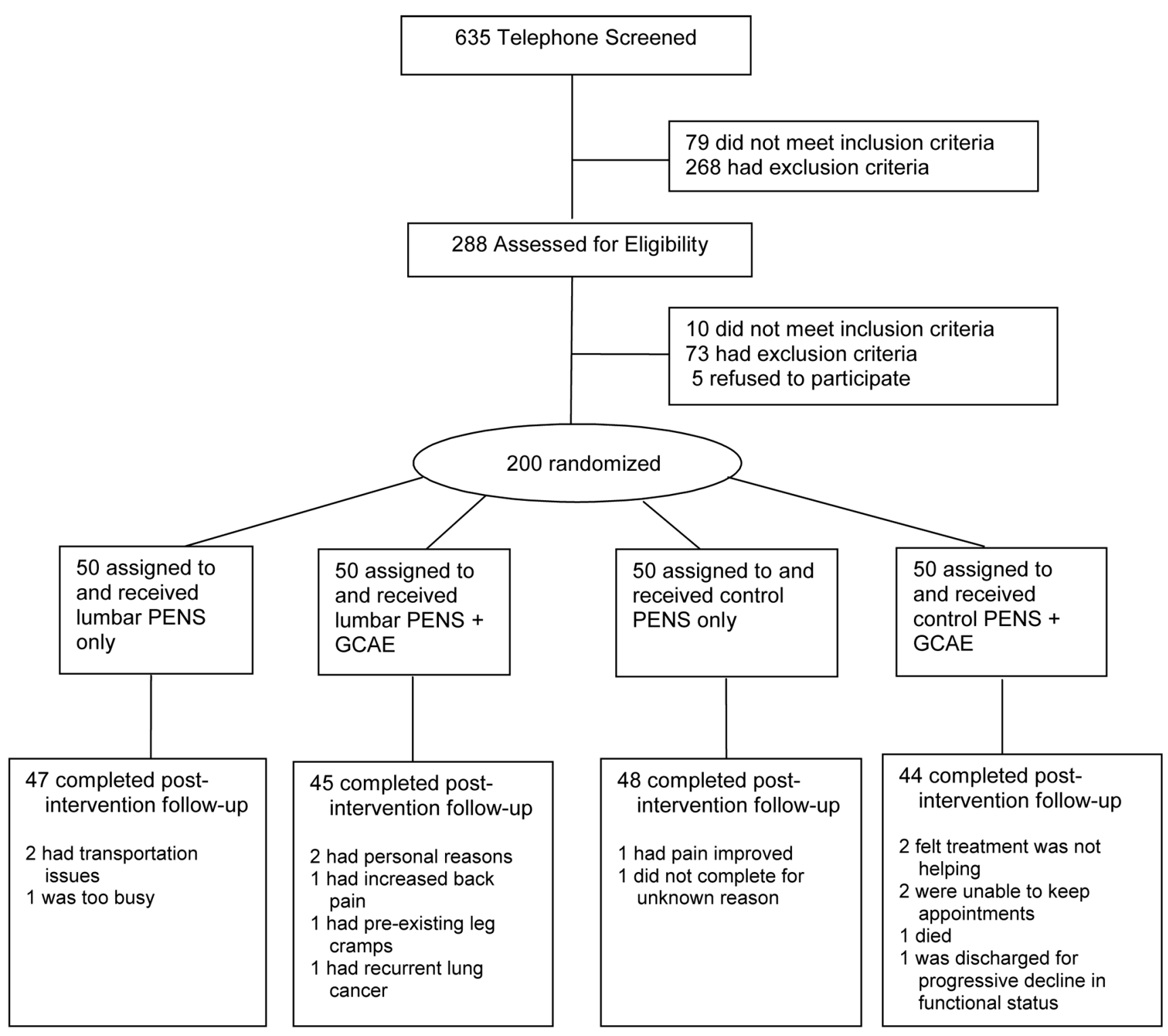

Figure 1.

Participant flow diagram. PENS = percutaneous electrical nerve stimulation; GCAE = general conditioning and aerobic exercise 

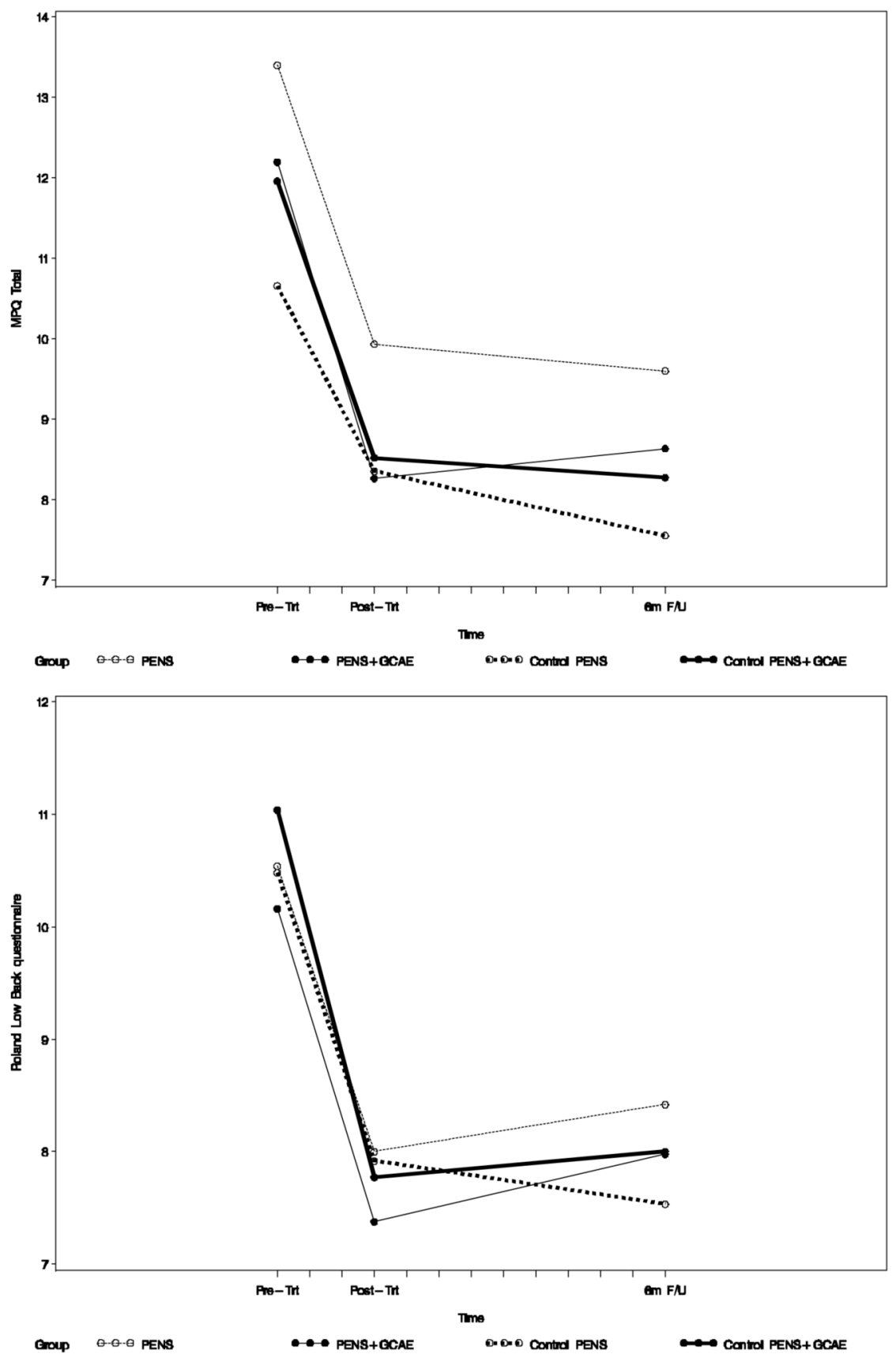

Figure 2.

Pain intensity (upper graph, McGill Pain Questionnaire short form) and self-rated disability (lower graph, Roland scale) at baseline, post-intervention, and 6 months. 


\section{Table 1}

\section{Inclusion and Exclusion Criteria}

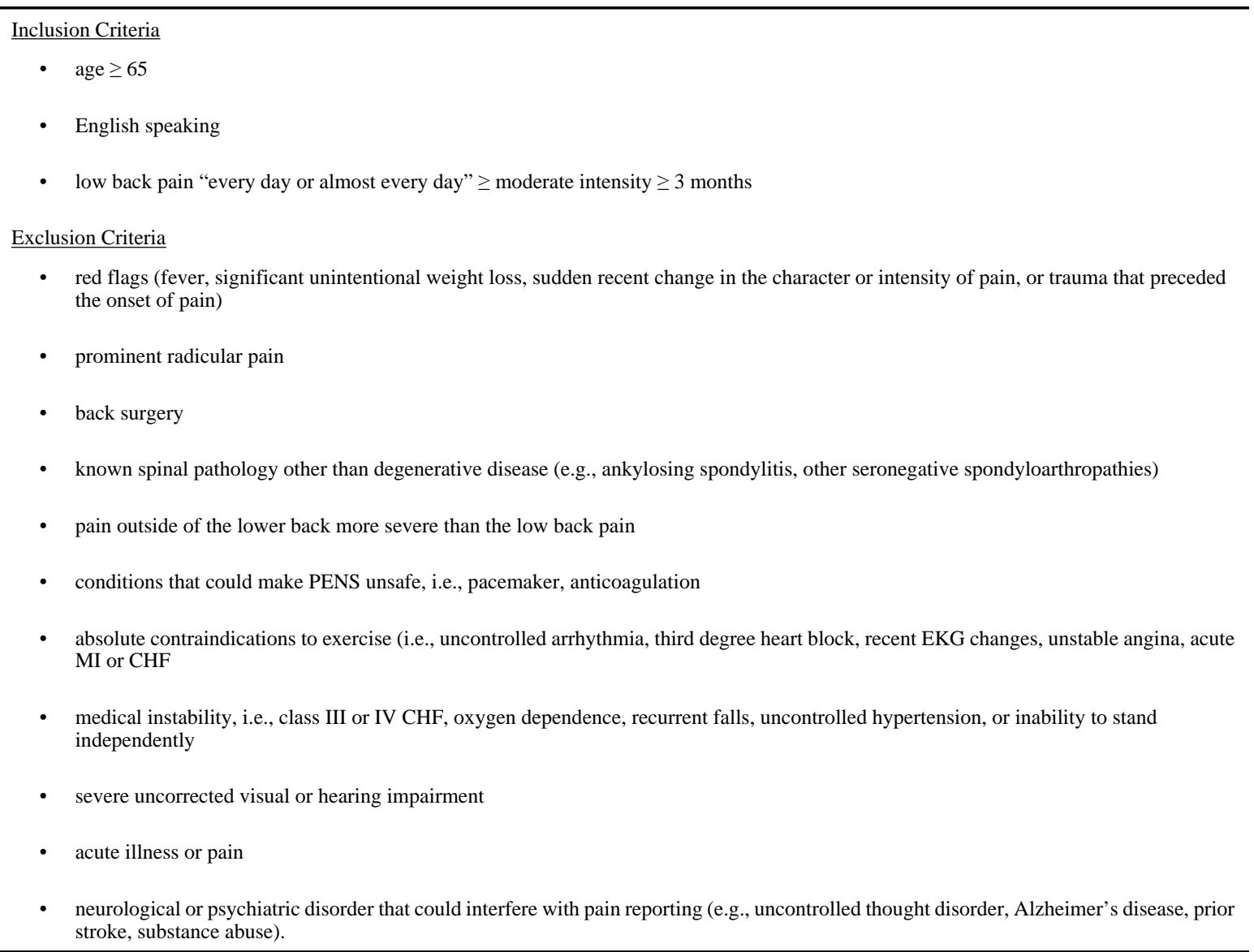


Table 3

Table 3A: Post-Intervention between-group comparisons adjusted for baseline value of the outcome: pairwise difference \pm standard error (p-value) for continuous outcomes; (p-value) only for categorical outcomes [effect size]

$\begin{array}{cc}\text { PENS vs Control-PENS } & \begin{array}{c}\text { PENS+GCAE vs } \\ \text { Control PENS } \\ \text { +GCAE }\end{array} \\ & \text { PENS+CGAE vs PENS }\end{array}$

Control PENS
+CGAE vs Control PENS

Post-Intervention:

Primary Outcomes: Pain and Function

MPQ Total

Roland questionnaire

$\underline{\text { Secondary Outcomes: Pain }}$

Average pain past week ${ }^{*}$

Strongest pain past week ${ }^{*}$

Secondary Outcomes: Psychological

GDS total score

CSQ catastrophizing score

FAB physical activities

Chronic pain self-efficacy

SF-36 composite mental health

Secondary Outcomes: Physical Function

Usual pace gait speed

Chair rise time

Stair climb time

Secondary Outcomes: Other

Pittsburgh sleep score

SF-36 composite physical health

Global change in condition

$\begin{array}{cc}0.5 \pm 1.4[.07] & -0.6 \pm 1.5[.08] \\ (0.7111) & (0.6841) \\ 0.1 \pm 0.9[.03] & 0.2 \pm 0.9[.04] \\ (0.8938) & (0.8501)\end{array}$

$-0.0 \pm 0.2[.01]$

(0.9333)

$-0.0 \pm 0.2[.01]$

$0.1 \pm 0.2[.16]$

(0.5157)

(0.9808)

$-0.2 \pm 0.6[.04]$

(0.7565)

$0.2 \pm 0.2[.18]$

$-0.1 \pm 0.2[.11]$

(0.4802)

$-0.1 \pm 0.3[.07]$

(0.6944)

$-2.4 \pm 3.0[.14]$

(0.4253)

$0.5 \pm 2.3[.03]$

(0.8406)

(0.2491)

$0.2 \pm 0.3[.09]$

(0.6088)

$-1.7 \pm 3.1[.10]$

(0.5881)

$-1.5 \pm 2.4[.11]$

(0.5268)

$$
\begin{gathered}
-0.01 \pm 0.01[.10] \\
(0.5952) \\
-0.3 \pm 0.3[.10] \\
(0.3402) \\
-0.3 \pm 1.1[.03] \\
(0.7938)
\end{gathered}
$$

$$
\begin{gathered}
0.0 \pm 0.5[.02] \\
(0.9156) \\
-5.3 \pm 4.4[.19] \\
(0.2258)
\end{gathered}
$$

-----\$

$$
\begin{gathered}
-1.4 \pm 1.4[.19] \\
(0.3230) \\
-0.2 \pm 0.9[.04] \\
(0.8302)
\end{gathered}
$$

$$
\begin{gathered}
-0.3 \pm 1.4[.04] \\
(0.8339) \\
-0.2 \pm 0.9[.05] \\
(0.7830)
\end{gathered}
$$

$\begin{array}{cc}-0.0 \pm 0.2[.00] & -0.0 \pm 0.2[.01] \\ (0.9970) & (0.9471) \\ -0.0 \pm 0.2[.05] & 0.1 \pm 0.2[.13] \\ (0.8681) & (0.6173)\end{array}$

$$
\begin{gathered}
-0.7 \pm 0.6[.16] \\
(0.2058) \\
0.2 \pm 0.2[.14] \\
(0.3478) \\
-0.6 \pm 0.3[.37] \\
(0.0426) \\
2.8 \pm 3.1[.16] \\
(0.3664) \\
-0.7 \pm 2.3[.05] \\
(0.7641)
\end{gathered}
$$$$
-0.0 \pm 0.6[.01]
$$$$
\text { (0.9357) }
$$$$
-0.1 \pm 0.2[.14]
$$$$
\text { (0.3530) }
$$$$
-0.9 \pm 0.3[.54]
$$$$
\text { (0.0039) }
$$$$
\text { 2.1 } \pm 3.1 \text { [.12] }
$$$$
\text { (0.5043) }
$$$$
1.3 \pm 2.3[.09]
$$$$
\text { (0.5885) }
$$ 


\begin{tabular}{|c|c|c|c|c|}
\hline & PENS vs Control-PENS & $\begin{array}{l}\text { PENS+GCAE vs } \\
\text { Control PENS } \\
\text { +GCAE }\end{array}$ & PENS+CGAE vs PENS & $\begin{array}{c}\text { Control PENS } \\
\text { +CGAE vs } \\
\text { Control PENS }\end{array}$ \\
\hline & $(0.9633)$ & $(0.3253)$ & $(0.9936)$ & $(0.3009)$ \\
\hline \multicolumn{5}{|c|}{$\begin{array}{l}\text { Table 3B: } 6 \text { month between-group comparisons adjusted for baseline value of the outcome: pairwise difference } \pm \text { standard error (p-value) } \\
\text { for continuous outcomes; (p-value) only for categorical outcomes }\end{array}$} \\
\hline & PENS vs Control-PENS & $\begin{array}{l}\text { PENS+GCAE vs } \\
\text { Control PENS } \\
\text { +GCAE }\end{array}$ & PENS+GCAE vs PENS & $\begin{array}{c}\text { Control PENS } \\
\text { +CGAE vs } \\
\text { Control PENS }\end{array}$ \\
\hline \multicolumn{5}{|l|}{ After 6 Months: } \\
\hline \multicolumn{5}{|c|}{ Primary Outcomes: Pain and Function } \\
\hline \multirow[t]{2}{*}{ MPQ Total } & $1.0 \pm 1.5[.14]$ & $-0.2 \pm 1.5[.02]$ & $-0.5 \pm 1.5[.07]$ & $0.6 \pm 1.5[.09]$ \\
\hline & $(0.4847)$ & $(0.9171)$ & $(0.7129)$ & $(0.6672)$ \\
\hline \multirow[t]{2}{*}{ Roland questionnaire } & $1.1 \pm 0.9[.23]$ & $0.4 \pm 0.9[.09]$ & $-0.4 \pm 0.9[.08]$ & $0.3 \pm 0.9[.05]$ \\
\hline & $(0.2437)$ & $(0.6545)$ & $(0.6704)$ & $(0.7870)$ \\
\hline \multicolumn{5}{|l|}{ Secondary Outcomes: Pain } \\
\hline \multirow[t]{2}{*}{ Average pain past week ${ }^{*}$} & $0.2 \pm 0.2[.30]$ & $-0.1 \pm 0.2[.07]$ & $-0.2 \pm 0.2[.25]$ & $0.1 \pm 0.2[.12]$ \\
\hline & $(0.1458)$ & $(0.7435)$ & $(0.2248)$ & $(0.5747)$ \\
\hline \multirow[t]{2}{*}{ Strongest pain past week ${ }^{*}$} & $0.4 \pm 0.2[.43]$ & $-0.0 \pm 0.2[.02]$ & $-0.5 \pm 0.2[.52]$ & $-0.1 \pm 0.2[.07]$ \\
\hline & $(0.0913)$ & $(0.9354)$ & $(0.0435)$ & $(0.7992)$ \\
\hline \multicolumn{5}{|l|}{ Secondary Outcomes: Psychological } \\
\hline \multirow[t]{2}{*}{ GDS total score } & $0.9 \pm 0.6[.20]$ & $-0.2 \pm 0.6[.04]$ & $-0.8 \pm 0.6[.17]$ & $0.3 \pm 0.6[.08]$ \\
\hline & $(0.1228)$ & $(0.7346)$ & $(0.1946)$ & $(0.5650)$ \\
\hline \multirow[t]{2}{*}{ CSQ catastrophizing score } & $0.0 \pm 0.2[.01]$ & $0.2 \pm 0.2[.22]$ & $-0.0 \pm 0.2[.03]$ & $-0.2 \pm 0.2[.23]$ \\
\hline & $(0.9434)$ & $(0.1732)$ & $(0.8670)$ & $(0.1420)$ \\
\hline \multirow[t]{2}{*}{ FAB physical activities } & $0.6 \pm 0.3[.37]$ & $0.2 \pm 0.3[.12]$ & $-0.7 \pm 0.3[.42]$ & $-0.3 \pm 0.3[.16]$ \\
\hline & $(0.0477)$ & $(0.5244)$ & $(0.0279)$ & $(0.3850)$ \\
\hline \multirow[t]{2}{*}{ Chronic pain self-efficacy } & $-3.7 \pm 3.1[.21]$ & $2.2 \pm 3.2[.13]$ & $5.1 \pm 3.2[.29]$ & $-0.8 \pm 3.2[.05]$ \\
\hline & $(0.2393)$ & $(0.4961)$ & $(0.1087)$ & $(0.8047)$ \\
\hline \multirow[t]{2}{*}{ SF-36 composite mental health } & $-4.2 \pm 2.4[.31]$ & $-0.4 \pm 2.4[.03]$ & $3.0 \pm 2.4[.22]$ & $-0.8 \pm 2.4[.06]$ \\
\hline & $(0.0782)$ & $(0.8626)$ & $(0.2159)$ & $(0.7352)$ \\
\hline \multicolumn{5}{|l|}{$\begin{array}{l}\text { Secondary Outcomes: Physical } \\
\text { Function }\end{array}$} \\
\hline \multirow[t]{2}{*}{ Usual pace gait speed } & $-0.01 \pm 0.01[.10]$ & $0.00 \pm 0.02[.00]$ & $0.01 \pm 0.02[.10]$ & $0.00 \pm 0.02[.00]$ \\
\hline & $(0.5238)$ & $(0.9903)$ & $(0.4544)$ & $(0.9189)$ \\
\hline \multirow[t]{2}{*}{ Chair rise time } & $0.5 \pm 0.3[.18]$ & $0.1 \pm 0.3[.03]$ & $-0.3 \pm 0.3[.13]$ & $0.1 \pm 0.3[.02]$ \\
\hline & $(0.1044)$ & $(0.7642)$ & $(0.2429)$ & $(0.8800)$ \\
\hline \multirow[t]{2}{*}{ Stair climb time } & $1.6 \pm 1.2[.14]$ & $1.4 \pm 1.2[.12]$ & $-0.8 \pm 1.2[.07]$ & $-0.6 \pm 1.2[.05]$ \\
\hline & $(0.1713)$ & $(0.2427)$ & $(0.5021)$ & $(0.6137)$ \\
\hline \multicolumn{5}{|l|}{$\underline{\text { Secondary Outcomes: Other }}$} \\
\hline Pittsburgh sleep score & $0.2 \pm 0.5[.08]$ & $0.5 \pm 0.5[.16]$ & $0.3 \pm 0.5[.08]$ & $-0.0 \pm 0.5[.00]$ \\
\hline
\end{tabular}




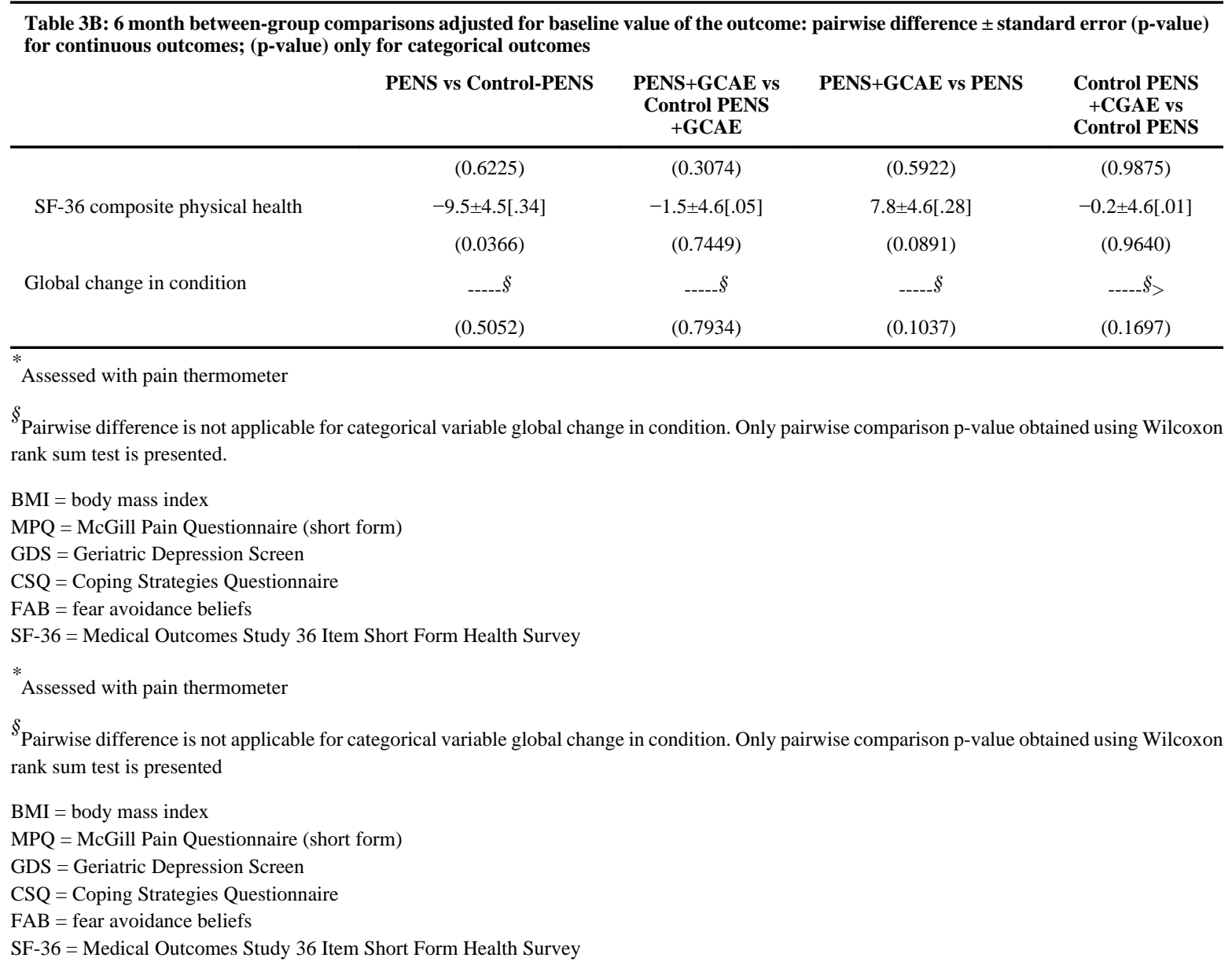


Table 4

Baseline to post-intervention and 6-month change in outcomes: mean \pm standard deviation or $\mathrm{N}(\%)$ (p-value)

\begin{tabular}{|c|c|c|c|c|}
\hline & PENS Only & PENS+CGAE & Sham Only & Sham+CGAE \\
\hline \multicolumn{5}{|c|}{ Baseline to Post-Intervention Change in: } \\
\hline \multicolumn{5}{|l|}{ Primary Outcomes: Pain and Function } \\
\hline \multirow[t]{2}{*}{ MPQ Total } & $-2.9 \pm 9.2[.40]$ & $-4.1 \pm 8.2[.56]$ & $-2.3 \pm 6.3[.31]$ & $-3.1 \pm 7.9[.42]$ \\
\hline & $(0.0344)$ & $(0.0017)$ & $(0.0145)$ & $(0.0123)$ \\
\hline \multirow[t]{2}{*}{ Roland questionnaire } & $-2.6 \pm 4.5[.56]$ & $-2.6 \pm 4.6[.56]$ & $-2.7 \pm 3.8[.59]$ & $-3.0 \pm 4.7[.65]$ \\
\hline & $(0.0002)$ & $(0.0005)$ & $(<.0001)$ & $(0.0001)$ \\
\hline \multicolumn{5}{|l|}{ Secondary Outcomes: Pain } \\
\hline \multirow[t]{2}{*}{ Average pain past week ${ }^{*}$} & $-0.7 \pm 1.1[.89]$ & $-0.7 \pm 0.9[.86]$ & $-0.6 \pm 0.7[.72]$ & $-0.6 \pm 1.2[.77]$ \\
\hline & $(<.0001)$ & $(<.0001)$ & $(<.0001)$ & $(0.0012)$ \\
\hline \multirow[t]{2}{*}{ Strongest pain past week ${ }^{*}$} & $-0.7 \pm 1.3[.75]$ & $-0.7 \pm 1.4[.74]$ & $-0.6 \pm 1.1[.72]$ & $-0.5 \pm 1.1[.57]$ \\
\hline & $(0.0008)$ & $(0.0023)$ & $(0.0002)$ & $(0.0054)$ \\
\hline \multicolumn{5}{|l|}{ Secondary Outcomes: Psychological } \\
\hline \multirow[t]{2}{*}{ GDS total score } & $0.3 \pm 3.2[.06]$ & $-0.4 \pm 2.6[.08]$ & $-0.2 \pm 2.8[.05]$ & $-0.3 \pm 3.2[.07]$ \\
\hline & $(0.5901)$ & $(0.3709)$ & $(0.6034)$ & $(0.5155)$ \\
\hline \multirow[t]{2}{*}{ CSQ catastrophizing score } & $-0.3 \pm 0.9[.27]$ & $0.0 \pm 0.9[.04]$ & $0.1 \pm 1.0[.05]$ & $-0.1 \pm 0.8[.13]$ \\
\hline & $(0.0266)$ & $(0.7518)$ & $(0.7269)$ & $(0.2430)$ \\
\hline \multirow[t]{2}{*}{ FAB physical activities } & $-0.1 \pm 1.3[.08]$ & $-0.6 \pm 1.4[.41]$ & $0.2 \pm 1.8[.11]$ & $-1.0 \pm 1.8[.64]$ \\
\hline & $(0.5382)$ & $(0.0032)$ & $(0.5174)$ & $(0.0005)$ \\
\hline \multirow[t]{2}{*}{ Chronic pain self-efficacy } & $3.2 \pm 16.7[.19]$ & $5.7 \pm 13.4[.33]$ & $4.9 \pm 16.1[.28]$ & $7.9 \pm 15.5[.45]$ \\
\hline & $(0.1902)$ & $(0.0070)$ & $(0.0425)$ & $(0.0016)$ \\
\hline \multirow[t]{2}{*}{ SF-36 composite mental health } & $1.5 \pm 12.0[.11]$ & $-0.3 \pm 11.4[.02]$ & $-0.1 \pm 10.8[.01]$ & $2.8 \pm 13.7[.20]$ \\
\hline & $(0.3863)$ & $(0.8421)$ & $(0.9436)$ & $(0.1847)$ \\
\hline \multicolumn{5}{|c|}{ Secondary Outcomes: Physical Function } \\
\hline \multirow[t]{2}{*}{ Usual pace gait speed } & $0.05 \pm 0.07[.50]$ & $0.07 \pm 0.07[.70]$ & $0.06 \pm 0.08[.60]$ & $0.08 \pm 0.08[.80]$ \\
\hline & $(<.0001)$ & $(<.0001)$ & $(<.0001)$ & $(<.0001)$ \\
\hline \multirow[t]{2}{*}{ Chair rise time } & $-0.9 \pm 2.4[.31]$ & $-0.7 \pm 1.1[.25]$ & $-0.4 \pm 1.3[.24]$ & $-1.5 \pm 3.7[.55]$ \\
\hline & $(0.0232)$ & $(0.0001)$ & $(0.1424)$ & $(0.0122)$ \\
\hline \multirow[t]{2}{*}{ Stair climb time } & $-1.3 \pm 6.2[.11]$ & $-0.9 \pm 4.9[.08]$ & $-1.3 \pm 5.9[.12]$ & $-2.2 \pm 6.0[.19]$ \\
\hline & $(0.1533)$ & $(0.2541)$ & $(0.1199)$ & $(0.0252)$ \\
\hline \multicolumn{5}{|l|}{ Secondary Outcomes: Other } \\
\hline \multirow[t]{2}{*}{ Pittsburgh sleep score } & $-0.2 \pm 2.0[.06]$ & $0.02 \pm 2.3[.01]$ & $0.0 \pm 2.7[.00]$ & $-0.7 \pm 2.3[.22]$ \\
\hline & $(0.5070)$ & $(0.9486)$ & $(1.0000)$ & $(0.0445)$ \\
\hline \multirow[t]{2}{*}{ SF-36 composite physical health } & $-1.1 \pm 20.7[.04]$ & $3.9 \pm 25.8[.14]$ & $5.9 \pm 23.8[.21]$ & $6.9 \pm 22.7[.25]$ \\
\hline & $(0.7257)$ & $(0.3103)$ & $(0.0909)$ & $(0.0489)$ \\
\hline \multicolumn{5}{|l|}{ Global change in condition } \\
\hline Deterioration & $1(2.1)$ & $1(2.2)$ & $0(0.0)$ & $0(0.0)$ \\
\hline No improvement & $12(25.5)$ & $8(17.8)$ & $8(17.7)$ & $6(13.6)$ \\
\hline Minor improvement & $7(14.9)$ & $10(22.2)$ & $13(27.1)$ & $9(20.5)$ \\
\hline
\end{tabular}




\begin{tabular}{|c|c|c|c|c|}
\hline & PENS Only & PENS+CGAE & Sham Only & Sham+CGAE \\
\hline Moderate improvement & $13(27.7)$ & $15(33.3)$ & $16(33.3)$ & $15(34.1)$ \\
\hline Major improvement & $14(29.8)$ & $11(24.4)$ & $11(22.9)$ & $14(31.8)$ \\
\hline \multicolumn{5}{|l|}{ Baseline to 6-month Change in: } \\
\hline \multicolumn{5}{|c|}{ Primary Outcomes: Pain and Function } \\
\hline \multirow[t]{2}{*}{ MPQ Total } & $-3.4 \pm 7.4[.47]$ & $-3.8 \pm 8.9[.51]$ & $-3.3 \pm 7.4[.45]$ & $-3.1 \pm 7.1[.41]$ \\
\hline & $(0.0041)$ & $(0.0075)$ & $(0.0044)$ & $(0.0093)$ \\
\hline \multirow[t]{2}{*}{ Roland questionnaire } & $-2.1 \pm 4.2[.44]$ & $-2.1 \pm 4.3[.45]$ & $-3.0 \pm 4.7[.64]$ & $-2.8 \pm 5.3[.60]$ \\
\hline & $(0.0025)$ & $(0.0027)$ & $(0.0001)$ & $(0.0022)$ \\
\hline \multicolumn{5}{|l|}{$\underline{\text { Secondary Outcomes: Pain }}$} \\
\hline \multirow[t]{2}{*}{ Average pain past week ${ }^{*}$} & $-0.5 \pm 1.1[.57]$ & $-0.6 \pm 1.1[.73]$ & $-0.6 \pm 0.8$ & $-0.5 \pm 1.1$ \\
\hline & $(0.0094)$ & $(0.0004)$ & $(<.0001)[.70]$ & $(0.0040)[.64]$ \\
\hline \multirow[t]{2}{*}{ Strongest pain past week ${ }^{*}$} & $-0.4 \pm 1.4[.48]$ & $-0.8 \pm 1.4[.95]$ & $-0.6 \pm 1.1[.68]$ & $-0.6 \pm 1.2[.68]$ \\
\hline & $(0.0511)$ & $(0.0002)$ & $(0.0006)$ & $(0.0029)$ \\
\hline \multicolumn{5}{|l|}{$\underline{\text { Secondary Outcomes: Psychological }}$} \\
\hline \multirow[t]{2}{*}{ GDS total score } & $0.5 \pm 3.0[.12]$ & $-0.1 \pm 2.2[.02]$ & $-0.4 \pm 2.7[.09]$ & $-0.1 \pm 3.0[.01]$ \\
\hline & $(0.2431)$ & $(0.7861)$ & $(0.3317)$ & $(0.9155)$ \\
\hline \multirow[t]{2}{*}{ CSQ catastrophizing score } & $-0.1 \pm 1.0[.13]$ & $0.0 \pm 0.8[.01]$ & $0.1 \pm 0.8[.07]$ & $-0.1 \pm 0.8[.13]$ \\
\hline & $(0.3926)$ & $(0.9277)$ & $(0.5553)$ & $(0.2723)$ \\
\hline \multirow[t]{2}{*}{ FAB physical activities } & $0.1 \pm 1.6[.05]$ & $-0.6 \pm 1.5[.35]$ & $-0.4 \pm 1.7[.27]$ & $-0.9 \pm 1.5[.56]$ \\
\hline & $(0.7615)$ & $(0.0157)$ & $(0.0931)$ & $(0.0007)$ \\
\hline \multirow[t]{2}{*}{ Chronic pain self-efficacy } & $1.4 \pm 15.2[.08]$ & $5.7 \pm 17.6[.33]$ & $4.0 \pm 16.1[.23]$ & $4.1 \pm 16.7[.24]$ \\
\hline & $(0.5556)$ & $(0.0388)$ & $(0.1019)$ & $(0.1271)$ \\
\hline \multirow[t]{2}{*}{ SF-36 composite mental health } & $-1.8 \pm 15.5[.13]$ & $-0.2 \pm 13.7[.01]$ & $1.2 \pm 11.3[.09]$ & $1.5 \pm 13.9[.11]$ \\
\hline & $(0.4378)$ & $(0.9417)$ & $(0.4895)$ & $(0.5117)$ \\
\hline \multicolumn{5}{|c|}{ Secondary Outcomes: Physical Function } \\
\hline \multirow[t]{2}{*}{ Usual pace gait speed } & $0.04 \pm 0.07[.40]$ & $0.06 \pm 0.07[.60]$ & $0.05 \pm 0.09[.50]$ & $0.05 \pm 0.08[.50]$ \\
\hline & $(0.0008)$ & $(<.0001)$ & $(0.0016)$ & $(0.0002)$ \\
\hline \multirow[t]{2}{*}{ Chair rise time } & $-0.7 \pm 2.5[.27]$ & $-0.8 \pm 1.2[.28]$ & $-1.4 \pm 2.7[.53]$ & $-1.3 \pm 4.0[.49]$ \\
\hline & $(0.0660)$ & $(0.0001)$ & $(0.0017)$ & $(0.0512)$ \\
\hline \multirow[t]{2}{*}{ Stair climb time } & $0.8 \pm 7.5[.07]$ & $-0.4 \pm 5.4[.03]$ & $-1.1 \pm 6.7[.10]$ & $-2.1 \pm 6.5[.19]$ \\
\hline & $(0.4855)$ & $(0.6448)$ & $(0.2910)$ & $(0.0551)$ \\
\hline \multicolumn{5}{|l|}{ Secondary Outcomes: Other } \\
\hline \multirow[t]{2}{*}{ Pittsburgh sleep score } & $-0.4 \pm 2.7[.13]$ & $0.1 \pm 2.7[.03]$ & $-0.4 \pm 2.6[.12]$ & $-0.6 \pm 2.9[.18]$ \\
\hline & $(0.3169)$ & $(0.8271)$ & $(0.3327)$ & $(0.2333)$ \\
\hline \multirow[t]{2}{*}{ SF-36 composite physical health } & $-5.9 \pm 21.0[.21]$ & $4.4 \pm 25.3[.16]$ & $5.1 \pm 24.7[.18]$ & $8.5 \pm 27.4[.30]$ \\
\hline & $(0.0744)$ & $(0.2582)$ & $(0.1760)$ & $(0.0572)$ \\
\hline \multicolumn{5}{|l|}{ Global change in condition } \\
\hline Deterioration & $5(11.6)$ & $2(4.6)$ & $1(2.2)$ & $2(5.0)$ \\
\hline No improvement & $15(34.9)$ & $10(22.7)$ & $18(40.0)$ & $7(17.5)$ \\
\hline
\end{tabular}




\begin{tabular}{lcccc}
\hline & PENS Only & PENS+CGAE & Sham Only & Sham+CGAE \\
\hline Minor improvement & $6(14.0)$ & $8(18.2)$ & $6(13.3)$ & $11(27.5)$ \\
Moderate improvement & $10(23.3)$ & $15(34.1)$ & $13(28.9)$ & $9(22.5)$ \\
Major improvement & $7(16.3)$ & $9(20.5)$ & $7(15.6)$ & $11(27.5)$ \\
\hline
\end{tabular}

* Assessed with pain thermometer

$\mathrm{BMI}=$ body mass index

MPQ = McGill Pain Questionnaire (short form)

GDS $=$ Geriatric Depression Screen

CSQ $=$ Coping Strategies Questionnaire

$\mathrm{FAB}=$ fear avoidance beliefs

SF-36 = Medical Outcomes Study 36 Item Short Form Health Survey 